\title{
AVALIAÇÃO DO EFEITO DO HERBICIDA GLIFOSATO NA MICROBIOTA DO SOLO
}

\author{
JOÃO VIEIRA DE CASTRO JÚNIOR * \\ PEDRO ALBERTO SELBACH ** \\ MARCO ANTONIO ZÁCHIAAYUB ***
}

\begin{abstract}
Investigou-se o efeito causado pelo herbicida glifosato na microbiota do solo, utilizando Argissolo vermelho distrofico arênico. No solo, coletado entre 0 e $30 \mathrm{~cm}$ de profundidade, quantificou-se a taxa de $\mathrm{CO}_{2}$ produzida e as unidades formadoras de colônia (UFC) de bactérias e fungos. Foram utilizadas 5 cepas de fungos filamentosos pertencentes do gênero Fusarium, crescidos em meio de cultura Czapeck com adição de glifosato. Realizaram-se ensaios para determinar a capacidade de utilização do herbicida como substrato e a concentração máxima inibitória para as cepas de Fusarium. Observou-se que a introdução do herbicida no solo não apresentou efeito negativo sobre a microbiota e que a população de bactérias cultiváveis mostrouse mais numerosa que a de fungos. Dentre as cepas testadas nenhuma foi inibida pela presença do glifosato, mesmo em altas concentrações. Todas as cepas estudadas foram capazes de utilizar o herbicida como fonte de nutriente.
\end{abstract}

PALAVRAS-CHAVE: HERBICIDAS; GLIFOSATO; MICROBIOTA DO SOLO.

\footnotetext{
Biólogo, MSc Microbiologia Agrícola e do Ambiente, Instituto de Ciência e Tecnologia dos Alimentos, Universidade Federal do Rio Grande do Sul (UFRGS), RS (e-mail: joaovcj@hotmail.com).

** Agrônomo, Doutor em Ciência do Solo, Instituto de Solos, UFRGS, RS (e-mail: selbach@ufrgs.br).

*** Engenheiro Químico, PhD Biotecnologia, Instituto de Ciência e Tecnologia dos Alimentos, UFRGS, RS (e-mail: mazayub@ufrgs.br).
} 


\section{INTRODUÇÃO}

Devido ao aumento não-planificado da população humana e ao rápido desenvolvimento industrial, a presença de substâncias contaminantes do meio ambiente tornou-se grave problema. $O$ uso intensivo de produtos químicos, em sua maioria xenobióticos, tem provocado a formação e deposição de grandes quantidades de resíduos. Dentre esses produtos pode-se citar os herbicidas, que estão entre os produtos mais comercializados no mundo devido à necessidade de controle das ervas daninhas.

O glifosato, pesticida da classe dos herbicidas, apresenta elevada eficiência na eliminação de ervas daninhas. Trata-se de produto não-seletivo, sistêmico e pós-emergente, cuja venda contabiliza o total de US $\$ 1,2$ bilhão/ano (AMARANTE e SANTOS, 2002).

Os efeitos adversos decorrentes da introdução do glifosato no meio ambiente podem ser sentidos pela comunidade biótica, ocasionando desequilíbrios bioquímicos como, decomposição da matéria orgânica e ciclagem de nutrientes.

Os microrganismos, principalmente bactérias e fungos, têm sido descritos como os principais degradadores de matéria orgânica presente no solo e na água. A introdução de compostos químicos nesses ambientes acaba servindo como fonte de nutrientes, principalmente de carbono, nitrogênio e fósforo (MONTEIRO, 2001).

A ação dos microrganismos sobre substâncias xenobióticas presentes no meio ambiente constitui mecanismo de suma importância, sendo reconhecida como o principal fator que determina a taxa e a extensão em que os xenobióticos são degradados no ambiente. Além disso, a taxa de degradação é influenciada pela biomassa microbiana ativa e pela disponibilidade do composto para a degradação (BEIGEL e CHANNY, 1999).

A adaptação da população microbiana a diversos compostos químicos no ambiente, bem como os fenômenos de degradação podem ser explicados pela adaptação de um componente específico da comunidade microbiana que resulta numa atividade competitiva e subseqüente proliferação dessa população. Tal fenômeno pode ser explicado pelo resultado da interação entre substâncias químicas, microrganismos e condições ambientais (SOMASSUNDARAM, 1990).

Este trabalho teve por objetivo analisar o efeito decorrente da adição de glifosato na microbiota do solo, mediante liberação de $\mathrm{CO}_{2}$ e aumento da biomassa, bem como sua possível utilização como fonte de nutrientes.

\section{MATERIAL E MÉTODOS}

\subsection{SOLO}

Os experimentos foram conduzidos no laboratório de biotecnologia do Centro de Ciência e Tecnologia dos Alimentos e no laboratório de solos da Universidade Federal do Rio Grande do Sul (UFRGS). O solo utilizado, classificado como Argissolo Vermelho Distrófico Arênico (Unidade de Mapeamento Bom Retiro, RS), apresentava as seguintes características físico-químicas: $\mathrm{pH}\left(\mathrm{H}_{2} \mathrm{O}\right)$ 4,3; matéria orgânica 1,2\%; carbono 0,68\%; P $15 \mathrm{mg} \cdot \mathrm{L}^{-1}$, e K $24 \mathrm{mg} \cdot \mathrm{L}^{-1}$.

As amostras foram coletadas na Estação Experimental Agronômica situada no município de Eldorado do Sul, sendo o material peneirado e estocado em temperatura ambiente. No laboratório foram pesados $500 \mathrm{~g}$ (peso seco) de solo e colocados em potes respirométricos (volume 1,2 L), fechados hermeticamente, sendo completados com água destilada (quando necessário) para se atingir a capacidade de campo em torno de $80 \%$.

No primeiro experimento foram adicionados ao solo cinco compostos orgânicos e um mineral, individualmente: lodo de estação de tratamentos de efluentes (20 t.ha-1), glifosato (5 L.ha-1), herbicida GOAL (4 L.ha-1), esterco de galinha (15 t.ha-1), aparas de couro (15 tha th $^{-1}$ ), e composto mineral NPK (500 kg.ha-1 $)$. No segundo grupo de experimentos adicionou-se glifosato na 
sua formulação pura (95\% princípio ativo), na dosagem $100 \mathrm{mg} \mathrm{kg}^{-1}$ de solo, ou a formulação comercial (43\% princípio ativo $+66 \%$ surfactante) $100{\mathrm{~mL} . \mathrm{kg}^{-1}}$.

\subsection{AVALIAÇÃO DO EFEITO DO GLIFOSATO PELA LIBERAÇÃO DE $\mathrm{CO}_{2}$}

O efeito provocado pela adição dos materiais citados no item 2.1 foi avaliado de acordo com a metodologia descrita por ALEF (1995), que quantifica o $\mathrm{CO}_{2}$ desprendido na respiração microbiana.

Os potes com solo foram incubados em temperatura ambiente, sendo colocados no interior dos mesmos recipientes plásticos com $20 \mathrm{~mL}$ de $\mathrm{NaOH} 0,5 \mathrm{M}$. O $\mathrm{CO}_{2}$ liberado reagiu com a base, sendo quantificado aos 2, 4, 7, 14, 20 e 24 dias após o início da incubação no primeiro experimento, e aos 2, 4, 8, 11, 19 e 31 dias no segundo experimento.

Aos $20 \mathrm{~mL}$ de $\mathrm{NaOH}$ retirados dos recipientes plásticos e colocados em copos cilíndricos adicionou-se $1 \mathrm{~mL}$ de solução de $\mathrm{BaCl}_{2}(30 \% \mathrm{p} / \mathrm{v})$ com precipitação do $\mathrm{CO}_{2}$, usando-se 3 gotas de fenolftaleína como indicador. As amostras foram tituladas com $\mathrm{HCl} 0,5 \mathrm{M}$ para determinar a quantidade de $\mathrm{CO}_{2}$ que participou da reação. Efetuou-se o mesmo procedimento com potes sem adição de solo (branco), sendo o volume do ácido anotado e utilizado na equação 1:

$$
\mathrm{mg} \mathrm{CO} \cdot \mathrm{kg}^{-1}=(\mathrm{mL} \mathrm{HCl} \mathrm{Branco})-(\mathrm{mL} \mathrm{HCl} \text { tratamento }) \times \mathrm{N}(\mathrm{HCl}) \times \mathrm{Eq} \cdot \mathrm{C} \mathrm{CO}_{2}
$$

Todos os experimentos foram efetuados em duplicatas, utilizando-se solo sem adição de nenhum produto como testemunha-controle.

\subsection{QUANTIFICAÇÃO DE MICRORGANISMOS DO SOLO POR DILUIÇÃO SUCESSIVA EM PLACAS DE PETRI}

Realizou-se a quantificação microbiana segundo JAHNEL, CARDOSO e DIAS (1999), sendo transferidos $10 \mathrm{~g}$ de solo dos potes respirométricos para Erlenmeyer com $90 \mathrm{~mL}$ de água destilada esterilizada. Agitou-se o recipiente por 15 minutos, manualmente, retirou-se $1 \mathrm{~mL}$ da suspensão e homogenizou-se essa alíquota em tubos de ensaio com $9 \mathrm{~mL}$ de água esterilizada. Foram preparadas diluições para bactérias de $10^{-4}$ a $10^{-6}$ e para os fungos de $10^{-2}$ a $10^{-4}$.

Utilizou-se o meio ágar nutriente ( $5 \mathrm{~g}$ de peptona, $3 \mathrm{~g}$ de extrato de carne, $10 \mathrm{~g}$ de NaCl, $10 \mathrm{~g}$ de ágar/litro de água destilada) para bactérias e o meio de Martin ( $1 \mathrm{~g}$ de $\mathrm{KH}_{2} \mathrm{PO}_{4}, 1 \mathrm{~g}$ de $\mathrm{MgSO}_{4} \cdot 7 \mathrm{H}_{2} \mathrm{O}$, $5 \mathrm{~g}$ de peptona, $10 \mathrm{~g}$ de glicose, $0,033 \mathrm{~g}$ de rosa de bengala, $0,05 \mathrm{~g}$ de estreptomicina e $10 \mathrm{~g}$ de ágar/ litro água destilada).

Efetuou-se o plaqueamento com alça de Drigalsky, retirando $0,1 \mathrm{~mL}$ de cada diluição e espalhando em placas de Petri. As placas foram incubadas invertidas por 1 semana a $28^{\circ} \mathrm{C}$, sendo contadas as colônias formadas.

Todas as análises foram efetuadas no início e no final do experimento, em duplicatas.

\subsection{CONDIÇÕES DE CULTIVOS DAS CEPAS}

Para os ensaios sobre a influência do glifosato no crescimento de fungos foram utilizadas 5 cepas de fungos filamentosos, pertencentes ao gênero Fusarium (91148 F. oxysporum, $55.1 \mathrm{~F}$. oxysporum, 130 F. oxysporum, 132 Fusarium sp, 77 F. oxysporum). Todas as linhagens foram isoladas de solo de plantações da cana-de-açúcar e gentilmente cedidas pelo Laboratório de Genética e Biologia Molecular da Escola Superior de Agricultura Luiz de Queiroz (Piracicaba). As cepas cresceram em meio Czapeck (CZ), modificado segundo STROF, KUB e KAFARSKI (1997), contendo $30 \mathrm{~g}$ de glicose; 0,5 g de $\mathrm{MgSO}_{4} \cdot 7 \mathrm{H}_{2} \mathrm{O} ; 0,5 \mathrm{~g}$ de $\mathrm{KCl} ; 3 \mathrm{~g}$ de $\mathrm{NaNO}_{3} ; 0,01 \mathrm{~g}$ de $\mathrm{FeSO}_{4} ; 1 \mathrm{~g}$ de $\mathrm{KH}_{2} \mathrm{PO}_{4} /$ litro água destilada, suplementado com $30 \mathrm{mg} \cdot \mathrm{L}^{-1}$ de glifosato por cinco dias em temperatura ambiente. 


\subsection{DETERMINAÇÃO DA BIOMASSA POR PESO SECO}

Para quantificação da biomassa foram transferidos, após 5 dias de cultivo, $10 \mathrm{~mL}$ do meio de cultura Czapeck para tubos de centrifuga (volume $15 \mathrm{~mL}$ ), previamente secos e pesados.

O material foi colocado em centrifuga a $3500 \mathrm{rpm}$, a $4{ }^{\circ} \mathrm{C}$ por 15 minutos, sendo o sobrenadante descartado e adicionado água destilada até completar $10 \mathrm{~mL}$. Após realizar essa operação três vezes para lavagem das células, os tubos foram colocados em estufa a $60{ }^{\circ} \mathrm{C}$ para secagem até peso constante (STROF, KUB e KAFARSKI, 1997).

Todas as pesagens foram efetuadas em duplicatas, sendo a biomassa calculada pela diferença entre o peso final e o inicial.

\subsection{UTILIZAÇÃO DO GLIFOSATO COMO SUBSTRATO}

Para testar a habilidade das 5 cepas de fungos em utilizar o glifosato como fonte de nutriente preparou-se suspensão de esporos $2,6 \times 10^{7}$, diluída em água destilada. Inoculou-se a suspensão em $100 \mathrm{~mL}$ de meio CZ, suplementado com $100{\mathrm{mg} . \mathrm{L}^{-1}}$ de glifosato em Erlenmeyer de $250 \mathrm{~mL}$.

Colocou-se o material em agitador horizontal a $150 \mathrm{rpm}$, a $30^{\circ} \mathrm{C}$ durante treze dias, sendo retiradas alíquotas de $10 \mathrm{~mL}$ após $05^{\circ}$ e $13^{\circ}$. dia para quantificar o aumento da biomassa no decorrer do ensaio por peso seco.

Realizou-se o ensaio em duplicata nas seguintes condições: meio de cultura completo (controle), meio com adição de $10 \%$ de glicose, sem adição de glicose, sem adição de $\mathrm{KH}_{2} \mathrm{PO}_{4}$ e sem adição de $\mathrm{NaNO}_{3}$, sendo esses nutrientes substituídos pelo glifosato.

\subsection{DETERMINAÇÃO DA CONCENTRAÇÃO MÁXIMA INIBITÓRIA}

Para avaliar a concentração máxima inibitória de glifosato preparou-se uma solução de esporos $2,6 \times 10^{7}$, inoculada em $100 \mathrm{~mL}$ do meio de cultura CZ em Erlenmeyer (de $250 \mathrm{~mL}$ ), contendo glifosato em diferentes concentrações (10 mg.L $\left.\mathrm{L}^{-1}, 50 \mathrm{mg} \cdot \mathrm{L}^{-1} \mathrm{e} 100 \mathrm{mg} \cdot \mathrm{L}^{-1}\right)$. Preparou-se meio sem adição de glifosato como controle (STROF, KUB e KAFARSKI, 1997).

Os experimentos foram conduzidos sob agitação ( $150 \mathrm{rpm})$, a $30^{\circ} \mathrm{C}$ durante 5 dias, sendo verificado o aumento da biomassa por peso seco.

\subsection{ANÁLISES ESTATÍSTICAS}

Todos os resultados encontrados no presente trabalho foram submetidos ao teste Anova com fator duplo sem repetição, seguido pelo teste de Tukey a 5\% (ALEF, 1995).

\section{RESULTADOS E DISCUSSÃO}

Os resultados da atividade microbiana no período de 24 dias estão apresentados na Figura 1.

A adição de esterco elevou a atividade pela maior liberação de $\mathrm{CO}_{2}$, provavelmente por proporcionar mais estímulo e conseqüentemente aumento da microbiota quando comparado aos demais tratamentos. Tal fato evidencia que certos compostos são mais fáceis de serem metabolizados e utilizados como fonte de nutrientes e energia.

A evolução do $\mathrm{CO}_{2}$ do solo tem sido utilizada como índice de atividade microbiana, de biomassa ativa e, ainda, do metabolismo do carbono lábil do solo (SOUZA, FERREIRA e SILVA 1994).

Os resultados obtidos mostraram que nenhum composto utilizado no experimento exerceu efeito negativo na população microbiana quando comparados à taxa de produção de $\mathrm{CO}_{2}$ pela testemunha. 


\section{FIGURA 1 - EVOLUÇÃO DO $\mathrm{CO}_{2}$ COM ADIÇÃO DE DIFERENTES COMPOSTOS}

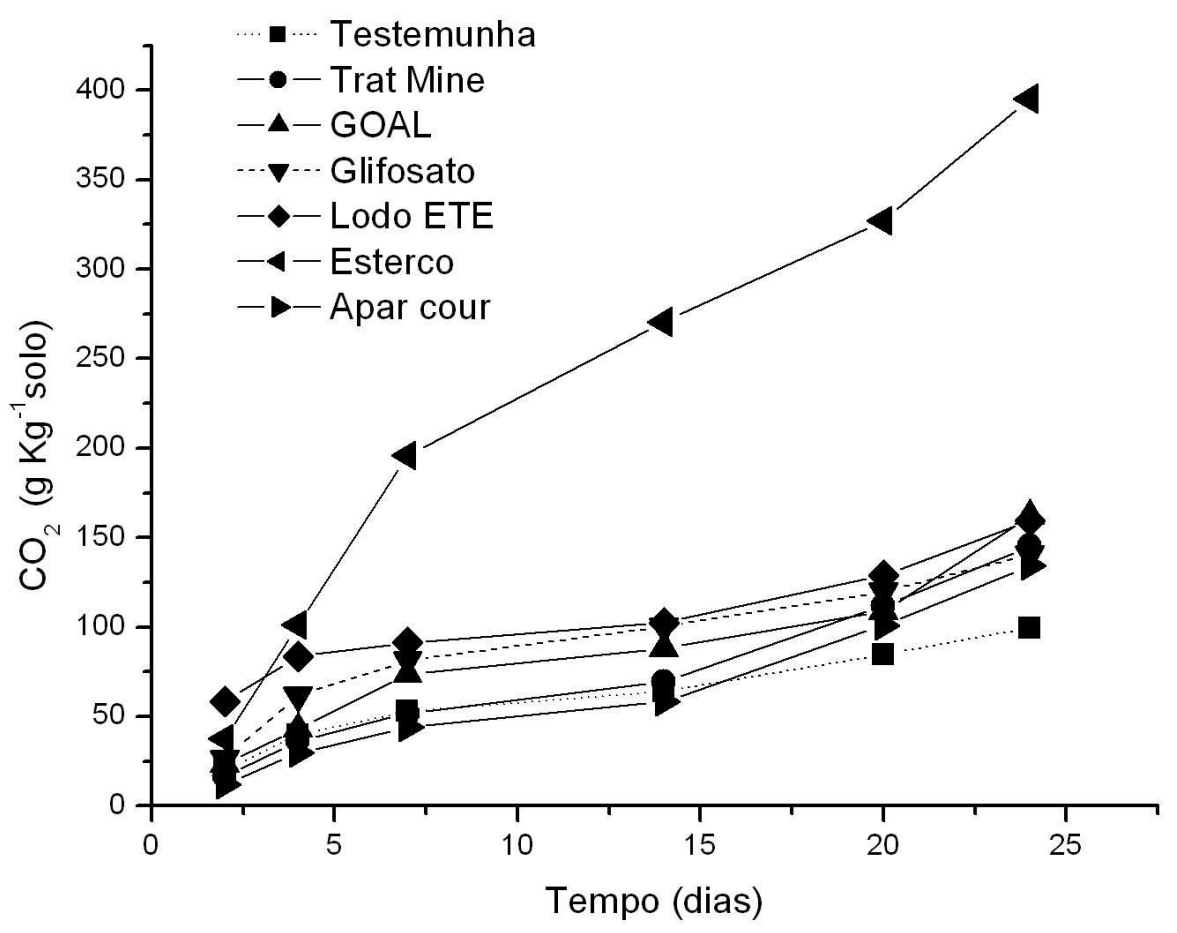

CHEAR, KIRKWOOD e LUM (1998) demonstraram que a taxa de metabolização dos xenobióticos varia de acordo com o tipo do solo. Em solos com grande quantidade de matéria orgânica ocorre baixa degradação, provavelmente pelo composto encontrar-se adsorvido. Já em solos arenosos existe rápida degradação pela baixa adsorção.

Comparando $0 \mathrm{CO}_{2}$ liberado no tratamento com o herbicida glifosato em relação aos demais (mineral, aparas, lodo e GOAL) observaram-se semelhanças quanto a atividade produzida pela microbiota presente nesse solo.

Os resultados encontrados para a atividade microbiana dos solos incubados com glifosato, avaliados pela técnica da evolução do $\mathrm{CO}_{2}$, constam da Figura 2 .

Verificou-se atividade microbiana em todos os tratamentos e que a adição do herbicida glifosato (formulação comercial ou na forma pura) não inibiu o crescimento da população, quando comparado ao resultado apresentado pela testemunha. Esse resultado assemelhou-se ao obtido por NICHOLSON e HIRSCH (1998) que estudaram o comportamento de glifosato e benomil, não tendo observado impacto negativo sobre a microbiota quando comparado ao controle (sem adição de pesticida). WARDLE e PARKINSON (1990) sugeriram que a produção de $\mathrm{CO}_{2}$ está relacionada com a decomposição do glifosato no solo. Resultados similares foram observados por ARAÚJO, MONTEIRO e ABARKELI (2003) ao descrever pequeno aumento no número de microrganismos, mas nenhum efeito positivo ou negativo da inoculação de glifosato em argissolo.

Segundo HANEY, SENSEMAN e HONS (2000), a aplicação de glifosato pode vir a estimular a atividade dos microrganismos do solo. Outros autores também consideram que pode haver aumento da atividade microbiana, mediante mineralização do carbono e nitrogênio.

As contagens dos microrganismos nas amostras de solo dos diferentes tratamentos com glifosato são apresentadas nas Tabelas 1 e 2, respectivamente. Observou-se variação no número de colônias entre os diferentes tipos de tratamento, evidenciando que o glifosato quando lançado ao ambiente pode proporcionar aumento na população microbiana. 


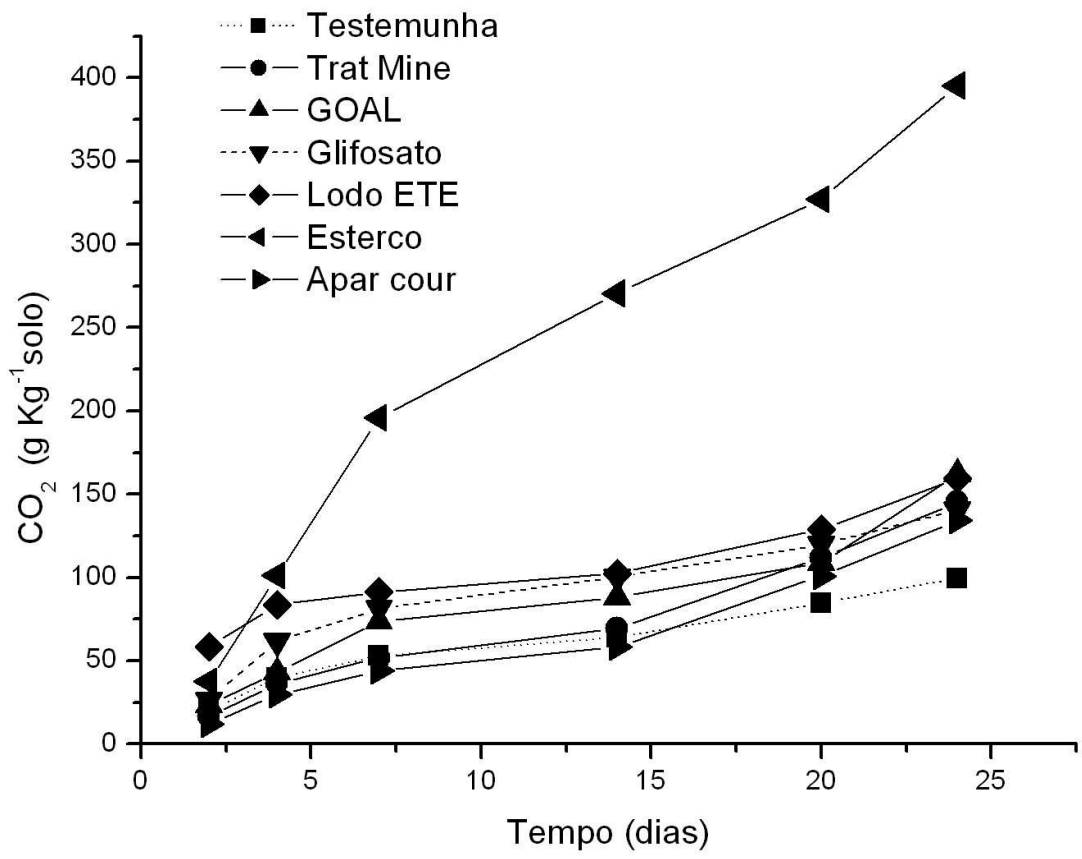

TABELA 1 - QUANTIFICAÇÃO DA POPULAÇÃO DE BACTÉRIAS DO SOLO TRATADO COM GLIFOSATO

\begin{tabular}{lll}
\hline Tratamento & UFC/g solo (dia 1) & UFC/g solo (dia 31) \\
\hline Testemunha & $1,78 \times 10^{5}$ & $2,63 \times 10^{5}$ \\
Puro $(95 \%)$ & $1,33 \times 10^{5}$ & $2,89 \times 10^{5}$ \\
Comercial (43\%) & $1,11 \times 10^{5}$ & $2,45 \times 10^{5}$ \\
\hline
\end{tabular}

UFC = Unidade formadora de colônia.

Segundo ANDERSON (1978), os compostos quando utilizados nas doses recomendadas não exercem efeitos adversos sobre os microrganismos do solo.

De acordo com os resultados obtidos, a adição do herbicida não exerceu efeito negativo na população de bactérias e fungos nem inibiu seu crescimento em nenhum dos tratamentos testados.

Não houve diferença significativa entre os tratamentos sem ou com adição do glifosato, assim como entre o número de microrganismos quantificados no solo com aplicação do produto puro e o comercial.

WARDLE e PARKINSON (1990) demonstraram que certos compostos podem influenciar direta ou indiretamente a população microbiana. Parece que os microrganismos apresentam capacidade de assimilação e degradação desses materiais, utilizando-os como fonte de nutrientes para seu crescimento. 


\section{TABELA 2 - QUANTIFICAÇÃO DA POPULAÇÃO DE FUNGOS DO SOLO TRATADO COM GLIFOSATO}

\begin{tabular}{lcc}
\hline Tratamento & UFC/g solo (dia 1) & UFC/g solo (dia 31) \\
\hline Testemunha & $6,7 \times 10^{2}$ & $7,8 \times 10^{2}$ \\
Puro $(95 \%)$ & $1,5 \times 10^{2}$ & $3,2 \times 10^{2}$ \\
Comercial $(43 \%)$ & $5,6 \times 10^{2}$ & $3,3 \times 10^{2}$ \\
\hline
\end{tabular}

UFC = Unidade formadora de colônia.

De maneira geral, o número de bactérias mostrou-se bem maior em todos os tratamentos que o número de fungos. Esses resultados contrastam com os descritos por ARAÚJO, MONTEIRO e ABARKELI (2003) ao estudar o impacto causado pelo glifosato na microbiota do solo. Esses não observaram diferença significativa no número de bactérias após 32 dias de experimento, verificando que a adição de glifosato aumentou a população fúngica quando comparado ao controle.

\section{TABELA 3 - QUANTIFICAÇÃO DA MASSA CELULAR SECA NOS DIFERENTES SUBSTRATOS TESTADOS (g.L-1)}

\begin{tabular}{c|ccccc|ccccc}
\hline & \multicolumn{7}{|c|}{ Cepas 5 dias } & \multicolumn{7}{|c}{ Cepas } & 13 dias & & \\
& 91148 & 55.1 & 77 & 130 & 132 & 91148 & 55.1 & 77 & 130 & 132 \\
\hline Meio completo & 11,4 & 2,37 & 7,92 & 5,18 & 4,67 & 70,13 & 8,25 & 23,88 & 76,62 & 5,98 \\
$10 \%$ de glicose & 0,21 & 0,1 & 0,26 & 0,22 & 0,13 & 2,14 & 0,78 & 1,28 & 1,02 & 1,13 \\
S/Glicose & 0,07 & 0,05 & 0,18 & 0,12 & 0,09 & 0,34 & 0,05 & 0,18 & 0,19 & 0,11 \\
S/NaNO & 0,16 & 0,17 & 1 & 0,07 & 0,98 & 5,38 & 1,29 & 1,31 & 3,95 & 1,32 \\
$\mathrm{~S}_{3} \mathrm{KH}_{2} \mathrm{PO}_{4}$ & 0,11 & 0,17 & 0,16 & 0,71 & 0,22 & 3,4 & 0,57 & 0,39 & 3,4 & 3,81 \\
\hline
\end{tabular}

De acordo com os resultados mostrados na Tabela 3 houve aumento da biomassa no decorrer do experimento. Isto sugere que o glifosato pode ser utilizado como fonte de nutrientes pelos microrganismos testados para o seu crescimento.

Segundo KONONOVA e NESMEYANOVA (2001) é cada vez mais comum a identificação de microrganismos capazes de mineralizar organofosforados (como o glifosato e outros xenobióticos) e utilizá-los como fonte de carbono e de nitrogênio, devido enzimas com alta especificidade a esses compostos.

O aumento da biomassa, mesmo na ausência de nitrogênio e fósforo, sugere que o glifosato serviu de suporte ao crescimento dos fungos filamentosos na ausência desses nutrientes. No entanto, nenhuma cepa apresentou crescimento significativo sem a adição de glicose em relação aos outros substratos estudados. Tal fato demonstra que para esse grupo de microrganismos, a glicose é essencial para o seu desenvolvimento.

TERNAN, McMULLAN e QUINN (1998) descreveram que microrganismos que degradam glifosato podem ser divididos em dois grupos. O primeiro grupo pode vir a utilizar o composto apenas como fonte de fósforo através das liases C-P e o segundo tem a capacidade de usá-los como aporte de nitrogênio e fósforo. 
Os resultados com relação ao efeito inibidor, provocado pela presença do glifosato aplicado em diferentes concentrações sobre os fungos testados, são apresentados na Figura 3. Os fungos filamentosos, de acordo com os resultados obtidos, não foram inibidos pelo glifosato. Em todos os ensaios em que foi adicionado o herbicida não foi constatado efeito negativo em relação aos resultados apresentados pelo meio controle (sem adição de glifosato).

\section{FIGURA 3 - BIOMASSA SECA DAS CEPAS DESENVOLVIDAS EM DIFERENTES CONCENTRAÇÕES DE GLIFOSATO}

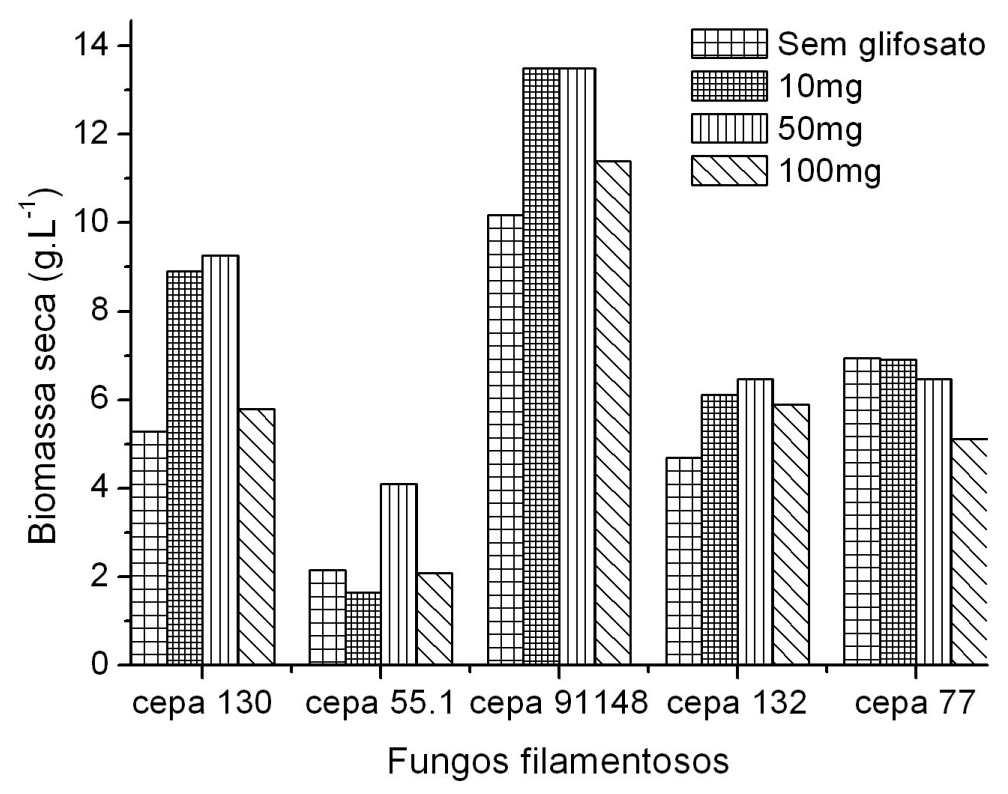

De acordo com os experimentos realizados por DIAZ, CARRILO e HONRUBIA (2003), o glifosato estimulou o crescimento micelial de $L$. deliciosus em termos de biomassa e diâmetro da colônia em doses inferiores a $1000 \mu \mathrm{g} \cdot \mathrm{g}^{-1}$. Acima dessa concentração o efeito desapareceu com significativa diminuição na biomassa e diâmetro da colônia.

Nos meios de culturas com adição de 50 e $100 \mathrm{mg}$ de glifosato houve o desenvolvimento de biomassa de forma similar que na sua ausência, demonstrando que a presença do herbicida não impediu o desenvolvimento das cepas em estudo (mesmo em altas concentrações). Esses resultados contrastam com os achados para outros fungos, descritos por WARDLE e PARKINSON (1992) que estudaram a alteração na interação interespecífica das espécies Mucor alpina, M. hiemalis, Trichoderma harzianum e Arthinium sphaerospermum. Na presença de glifosato até $200 \mu \mathrm{g} . \mathrm{g}^{-1}$, o crescimento e sobrevivência dos mesmos foram fortemente inibidos. LAATIKAINEN e TANSKI (2002) mostraram que o glifosato, testado com os fungos ectomicorrízicos em cultura pura, Hebeloma crustuliniforme, Laccaria laccata e Suillus tomentosum foram inibidos em concentrações acima de 10 ppm. Já Cenococcum geophilum, $H$. longicadum e $P$. tictorius evidenciaram inibição em concentrações abaixo de 100 ppm. Os resultados obtidos apontam para possível aplicação do gênero Fusarium oxysporum, mais especificamente das linhagens testadas neste trabalho, como potenciais biodegradadores de resíduos desse pesticida em ambientes naturais e contidos como, por exemplo, depósito de resíduos agrícolas contamindados. 


\section{CONCLUSÃO}

A presença do herbicida glifosato no solo não afetou negativamente a microbiota, sendo as bactérias mais numerosas que os fungos nos ensaios realizados. Os microrganismos foram capazes de utilizar o glifosato como substrato, no entanto é necessária a presença de glicose para o crescimento das cepas estudadas. O herbicida não apresentou efeito inibitório no crescimento dos fungos testados, mesmo em altas concentrações.

\section{ABSTRACT}

\section{EVALUATION OF THE EFFECT OF HERBICIDE GLYPHOSATE ON SOIL MICROBIOTA}

The effect caused by the herbicide glyphosate on soil microbiota was investigated in arsenic red dystrophic Argisol. In the soil collected from 0 to $30 \mathrm{~cm}$ of depth, was quantified the $\mathrm{CO}_{2}$ produced and colony forming unities (CFU) of bacteria and fungi. Five filamentous fungi strains belonging to Fusarium genre were grown on Czapeck medium with addition of glyphosate. The assays were conduced to determine whether these strains could use glyphosate as substrate for growth and also the inhibitory concentration for Fusarium strains. It was observed that the herbicide did not show any negative effect on the soil microbiota and that the population of bacteria was always higher than the fungi. Among the tested strains, no inhibition was verified by the addition of glyphosate, even at high concentrations. All studied strains were able to use the herbicide as a nutrient source for growth.

KEY-WORDS: HERBICIDES; GLYPHOSATE; SOIL MICROBIOTA.

\section{REFERÊNCIAS}

1 ALEF, K. Soil respiration. In: ALEF, K.; NANNIPIERI, D. Methods in applied soil microbiology and biochemistry. London: Academic Press, 1995. p. 214-216.

2 AMARANTE, O.P.; SANTOS, T.C. Glifosato: propriedades, toxicidade, usos e legislação. Química Nova, v. 25, n. 4, p. 589-593, 2002.

3 ANDERSON, J.P.E. Pesticides effects on non-target soil microorganisms. In: PESTICIDES microbiology. New York: Academic Press, 1978. p. 611-628.

4 ARAÚJO, A.S.F.; MONTEIRO, R.T.R.; ABARKELI, R.B. Effect of glyphosate in the microbial activity of two Brazilian soils. Chemosphere, v. 52, p. 799-804, 2003.

5 BEIGEL, C.; CHANNAY, M.P. Degradation of formulated and unformulated fungicide in soil. Soil Biology \& Biochemistry, v.31, n. 4 , p. 59-65, 1999.

6 CHEAR, U.B.; KIRKWOOD, R.C.; LUM, K.Y. Degradation of four commonly used pesticides in Malaysian agricultural soils. Journal Agric. Food Chem., v. 46, p. 1217-1223, 1998.

7 DÍAZ, G.; CARRILO, C.; HONRUBIA, M. Differential responses of ectomycorrhizal fungi to pesticides in pure culture. Cryptogamie Mycologie, v. 24, n. 3, p. 199-211, 2003.

8 HANEY, R.L.; SENSEMAN, A.S.; HONS, E.M. Effect of glyphosate on soil microbial activity and biomass. Weed Science, v.48, n.1, p. 89-93, 2000.

9 JAHNEL, M.C.; CARDOSO, E.J.B.N.; DIAS, C.T.S. Determinação do número mais provável de microrganismos do solo pelo método de plaqueamento por gotas. Revista Brasileira de Ciência do Solo, Viçosa, v.23, p. 553-559, 1999.

10 KONONOVA, S.V.; NESMEYANOVA, M.A. Phosphonates and their degradation by microorganisms. Biochemistry, v. 67, n. 2, p. 184-195, 2001.

11 LAATIKAINEN, T.; TANSKI, H.H. Mycorrhizal growth in pure culture in the presence of pesticides. Microbiological Research, v. 157, p. 127-137, 2002.

12 MONTEIRO, R.T.R. Biodegradação de pesticidas em solos brasileiros. In: VARGAS, M.C.; MARTINS, J.T. Biodegradação. Piracicaba: Emprapa Meio ambiente, 2001.

$13 \mathrm{NICHOLSON}$, P.S.; HIRSCH, P.R. The effects of pesticides on the diversity of culturable soil bacteria. Journal Applied Microbiology, v. 84, p. 551-558, 1998. 
14 SOMASSUNDARAM, L. Influence of pesticides metabolites on the development of soil microorganisms. Washington: American Chemical Society, 1990.

15 SOUZA, A.P.; FERREIRA, F.A.; SILVA, A.A. Respiração microbiana do solo sob doses de glifosato e imazapir. Planta Daninha, v. 17, n. 2, p. 245-262, 1994.

16 STROF, W.; KUB, K.; KAFARSKI, P. The ability of soil-borne fungi to degradate organophosphonate carbon to phosphorous bond. Applied Microbiology and Biotechnology, v. 48, p. 549-552, 1997.

17 TERNAN, N.G.; McMULLAN, G.; QUINN, P. Review: organohosphonates: occurrence, synthesis and biodegradation by microorganisms. World Journal of Microbiology and Biotechnology, v. 14, p. 635-647, 1998.

18 WARDLE, D.A.; PARKINSON, D. Influence of the herbicide glyphosate on soil microbial community structure. Plant and Soil, v. 122, n. 1, p.29-37, 1990.

19 WARDLE, D.A., PARKINSON, D. The influence of the herbicide glyphosate on interspecific interactions between four soil fungal species. Mycologial Research, v. 96, n. 3, p. 180-186, 1992.

\section{AGRADECIMENTOS}

Os autores agradecem ao Conselho Nacional de Desenvolvimento Científico e Tecnológico (CNPq) e à Coordenação de Aperfeiçoamento de Pessoal de Nível Superior (CAPES) pelo financiamento desta pesquisa. 